the best evidence that ample poison was injected into the wound. I believe that the subsequent potash treatment, both interally and externally, on which I solely depended in this case, had its action expedited by the stimulant effect of the brandy, and aided materially in perfecting the cure. The objects $I$ had in view were-1st, to remove, if not all, as much of the poison from the wound as was possible by suction; 2ud, to arrest the poison being carried into the system by the application of the several ligatures along the hand axd arm; 3rd, to destroy any portion of the poison that may have been left in the wound by the free application of the liquor potassæ. 4th. The liquor potassæ was given freely internally with the view of saturating the blood, so as to render it thoroughly alkaline, that any poison found in it migat be decomposed.* 5th. At the hospital the screw touriquet was applied, to supersede the other ligatures, as bein r likely to cause less pain than that produced by cords. The tourniquet was maintained for four hours continumisly; and, fearing that mortification would ensue if continued longer, it was then removed. After the application of the tourniquet, two of the largest veins on the back of the hand were opened with a lancet, and emptied of their contents, with the view of relieving the vessels of any prissned blood that they may have contained; and the haud wp to the elbow was immersed in warm water, concrining from one to eight drachins of the liquor potasse to tise gailon, for about four hours, to enconrage bleeding, and wabstituted for cold water, containing the same quantity of the liquor potassa, for the next four hours; and, as the veins continued to bleed more freely than was intended, the bleeding was arrested by pads and bandages. The potash Wath to tho arm was continued for eioht hours in all, with the hop that some portion of the potash might be absorbed through the skin, and destroy any poison that might have leen taken up between the wound and ligatures.

I would here observe, that sucking a poisoned wound, and especially that occasioned by a cobra, where the venom is so very powerful and energetic, will always be attended with risk to the operator, and most probably imperil two itres instead of one. Under these circumstances, to obviate the risk as much as possible, I would suggest that, in those cases where it is feasible, the pationt himself should be urged to suck ont the poison from the wound, so as to reduce and confine the peril to the individual who had the misfortune to be vitten.

I hope on a future occasion to detail a mode of treatment to be pursined in all such cases. Of course, there is nothing new in the sucking of a poisoned wound; this is well known to medical men generally. I only claim the fact of having brought it practically into successful play. But the potash treatment is original, and iay own, based on numemus actual experiments, carried out from time to time at mulch expense, trouble, and risk.

The accident is said to have occurred thus:-After I had ermine the snake, Goorooven seized it and thrust it, tail furemost, into the earthen chatty in which it was brought, and having placed the whole of the snake bodily into the ressel, he held its head with the thumb and forefinger of the left hand, and holding the cocoa-nut shell ready to shut the mouth of the chatty with his right hand. In letting o the head of the snake, he appears not to have been suficiently quick with the shell in covering up the chatty, and just as he let it go, the snake, which was in an excited state, flew at and seized the back of his index finger. The bite was severe, and but the work of a moment. The man himself became greatly plarmed, and, being alive to the rasuits of such accidents, alluded, in desponding terms, to isis wife and children. I had much to do in allaying his festrs and cheering him with hopes of recovery.

hese men, as a class, are a very rude set, and are fully wware of stich dangers, but from habit they soon grow reckless. In fact, I often wonder that accidents of the kind do not occur more frequently; and that they do occur is certain, though nothing is known of such occurrences, as the people live in the outskirts of the town or village, in amall, scattered communities, consisting of a dozen huts at nost, and, from erratic habits, are constantly changing their abodes from place to place, so as to render little or nothing known regarding them.

I believe this is the first authenticated instance in which z. man, fairly bitten by a fresh, vigorous cobra, recovered by

Vice The Lixcer, Día: 211, 1968, p. 557, and May 16th, p. 615 . rational treatment. It is a source of pleasure and thankfulness to me that I have been the humble instrument in saving this poor fellow's life, though it was at the risk of my own; and in the saving of the life of this single individual I feel that I have been amply rewarded for the trouble, risk, and expense I have been put to, in the several experiments which I have been conducting from time to time since 1866

Madras, 15th January, 1870.

\section{THE BOUGIE A BOULE AND THE BOUGIE OLIVAIRE.}

BY W. F. TEEVAN, ESQ., B.A., F.R.C.S., SURGEON TO THE WEST LONDOX HOSPITAL, ETC.

As no history or description of the Bougie à Boule, or of the Bougie Olivaire, has appeared in THE LANCET, a few words regarding these invaluable instruments may, perhaps, not prove uninteresting.

The bougie à boule was invented by Sir Charles Bell, by him called "ball bougie" and "urethra probe," and was made of metal. Fig. A is taken from Plate 3 in his work entitled "A Treatise on Diseases of the Urethra, \&c." Leroy d'Etiolles modified Sir Charles Bell's ball-staff by making it of an elastic material, which was a great improvement, as it permitted the bougie to adapt itself to the windings of a tortuous and deformed urethra. Fio. $\mathrm{B}$ represents the bougie a boule of Leroy d'Etiolles as now used in Paris, and is taken from one that I purchased at Lassèrre's, in the Avenue Victoria. About a dozen years ago a further modication and improvement was made in the bougie à boule by $\mathrm{Dr}$. Henry Dick, who had the head of the bougie made conical, with a sharp base. Fig. $c$ is a drawing taken from one of Dr. Dick's bougies, as made by Ernst some years ago. This bougie, with a graduated stem, is by far the most valuable, and is the one which will be found most useful in practice. It must not be forgotten that the bougie à boule is simply an instrument for the diagnosis of incipient strictures, and enables us to ascertain the exact pathological condition of the canal, for, on withdrawal, it will detect the slightest contraction, induration, or inelasticity of the mucous membrane.

As I was unable to make out the exact history of the bougie olivaire (Fig. D), I wrote to M. Auguste Mercier, who has kindly supplied me with the requisite information in the following extract from his letter: "Mais ces bougies resemblent tout à fait, pour la forme, aux bougies oedaliques de Lioutt, qui les a inventées au commencement du siècle." I had sent M. Mercier an illustration of two instruments which I cut out of Messrs. Maw's catalogue. The subjoined description of olivary bongies is by Desormeaux (“Dict. de Méd. et de Chir. Prat.," t. v., p. 437) :-

"Bovgres Olrvalres. - Ce sont des bougies coniques, dont la point est remplacée par un renflement en olive. Elles ont l'avantage de ne pas s'engager aussi facilement que les précédentes dans les plis et les crifices de la muqueuse urethrale, et d'exposer beaucoup moins aux fausses routes, \&e."

The bougie olivaire is now making rapid way in this country, and of the treatment of stricture by it and its slender sister, the filiform bougie, that can be said which I believe cannot be affirmed of any other method-that it is applicable to all cases of stricture, and is devoid of funereal associations. The treatment of stricture by the bougie olivaire is therefore the treatment, and all other methods 
merely auxiliaries. The olive head of the bougie, in the annexed woodcut (Fig. D) has been purposely much exaggerated in size in order to show how the instrument was constructed-by placing an olive-shaped head on a conical bougie.

For my knowledge of the bougie à boule $I$ am indebted to Dr. Henry Dick, whilst I became accidentally acquainted with the bougie olivaire at Lassèrre's. About five years ago I introduced these instruments into hospital practice, and brought them before the notice of several medical societies. For further information on the subject, I would refer to an article by me, "On the Diagnosis and Treatment of Stricture of the Urethra in its Early Stage," in the Brit. and For. Med.-Chir. Rev. for July, 1867, p. 232.

Portman-square, April, 1870.

\section{NOTES ON "LOCOMOTOR ATAXY," TABES DORSALIS.}

By. W. MOXON, M.D., F.R.C.P., ASSISTAYT-PHYSICTAIN to GUX's HOSPITAL.

$I_{T}$ will be a great pity if the disposition now shown to regard spinal diseases from a clinical point of view is allowed to pass out of fashion before all cases of cord disease are brought into clinical method. The state of our present knowledge of diseases of the cord is bewildering and disconcerting in the extreme. Surely one is right in saying this when one views the latest phase of the subject as shown in the contributions to Dr. Reynolds's "System of Medicine." 'The list which the able author of the contribution on Spinal Diseases gives is this:-

\begin{tabular}{l|l|} 
Meningitis. & Non-inflammatory Softening. \\
Myelitis. & Induration. \\
Congestion. & Atrophy and Hypertrophy. \\
Tetanus. & Tumour, \&c. \\
Irritation. & Concussion. \\
General Spinal Paralysis. & Compression. \\
Hysterical Paraplegia. & Caries of Vertebræ. \\
Reflex Paraplegia. & Spina Bifida. \\
Infantile Paralysis. & Epidemic Cerebro-spinal Me- \\
Hæmorrhage. & ningitis.
\end{tabular}

Elsewhere Locomotor A taxy is given among general nerrous diseases (although it seems surely as limited as epidemic cerebro-spinal meningitis, which is given among local dis eases). This list is plainly a comparison of incompatibles, and hence it is confusion. The several diseases are not diseases in the same import and meaning of the thing disease. Some of them-viz., general spinal paralysis, hysterical and reflex paraplegia, infantile paralysis, as well as irritation, tetanus, and locomotor ataxy - are groups of symptoms; I mean that they are characterised and recognised by the phenomena of the case as clinically observed. Others-such as hæmorrhage, softening, induration, meningitis, myelitis, tumour, concussion and compression-are not groups of symptoms, but are features of morbid anatomy.

I believe we cannot too clearly perceive, nor too urgently endeavour to rectify, the ill result which this confusion of incompatibles raises to cloud our clinical labours. The list should offer us good alternatives-such that we can, in the cases we have to name and tieat, go from the one alternative to another comparable alternative, until we arrive at that which our case most corresponds to. But how is one to settle whether a case is chronic myelitis or general spinal paralysis or induration? We see that the physician who instructs us puts these three in separate places as practically distinct; and yet we know that chronic myelitis will cause induration, and that induration will cause general spinal paralysis; so that induration and myelitis appear to be stages in the development of the sequences in any case of general spinal paralysis. And thus, with a case before us where a paralysis is general and spinal, we are confused, and not helped, when we should be assisted in our desire to view our case in harmony with the medical knowledge of our time.

Surely there is no need for this confusion. We can see by this time that the anatomical method is not only very incomplete in the dead subject, but is certainly utterly and hopelessly inapplicable in the living. Have we not been assuming too readily that the anatomical changes which occur in diseases are the best criteria of their natme? S. that our belief is set upon machinery, and tends to withdraw our study from processes which form and govern the machinery.

The way out of this confusion is plain, if not easy. The anatonical diseases of the type of tumour, meningitis, \&c. which are known by their post-mortem features, have also their clinical features; and these will fairly compare with the clinical diseases of the type of general spinal paralysis. These clinical features of anatomical diseases will surely be found to fall into such groups, under careful observation, that a practitioner may, when he meets any instance, learn the general experience on that group of symptoms; and so obtain an advantage which the phenomenal criteria of the disease give him in cases of general spinal and such-like paralysis, but which he can never have while he is left to guess his way to anatomical criteria-sueh as induration, softening, tubercle, or tumour.

It is altogether false to suppose, in the different examples of myelitis which we may meet with, that the inflammation that is common to them all serves for any practically useful tie of union between them. There are two sides to the practical importance of infiammation : first, the diagnostic; and, second, the therapeutic. But no one nowadays combats inflammation in his treatment of his cases-unless he knows no better; so that inflammation has lost its therapeutic importance; and as to its diagnostic importance, inflammation has to be analysed up by its variety of causes. At the bedside the one thing, inflammation, must be realised as of different essential natures, in the same way as by our several senses the one thing, motion, is realised-as light, sound, or touch; and as motion, which is dominant in coarse mechanical purposes, is lost out of sight in the special things-sound, light, \&c., -so inflammation, which is dominant in abscess-formation and other surgical affairs, is lost out of sight in rheumatic, syphilitic, and other diseases, even when they are attended with inflammatory phenomena-as sound is with motion. If this is true, then no useful end can be served by identifying cases of meningitis, myelitis, \&c., merely as infiammations of the enrd or meninges, even if we could recognise these states with certainty; and as in reality such changes are not recognised with certainty, I do not see what reason there is that should induce us still to put in chief place the fact of myelitis, even where mye. litis presumably exists. If the inflammation, when recognised, pointed out a certain line of practice, then there would be at least a strong motive for endeavouring to ascertain it clinically; or if the fact of the inflammation was $s 0$ sure as to enable us to fir our lnowledge of the case by it, then it would be desirable to keep that fact well in view, even if it did not help our treatment. But whereas we neither can certainly find out nor localise the inflammation, nor, if we could, should twe be any better able to treat our case, there surely is no reason why the endeavour to set our mutual recognition of cases, in total disregard of the inflammation, should not be made. I mean to say that the regulation of our views of cases of spinal disease, by the symptoms they show, would cause us no loss of any useful criteria in this class of diseases; for the most part the chief groups of them would remain unaltered, while we should obtain the great advantage of being able to proceed from the consideration of one alternative to that of another in determining individual cases by the certain method of recognising the symptoms of the case in point, and directly identifing them with roreed groups of symptoms.

I think we need not doubt that all cases of spinal disease, when so studied, would resolve themselves into classes, or at least follow certain types. What Duchenne bas developed in the cases of glosso-laryngeal paralysis, general spinal paralysis, locomotor ataxy, $S_{c}$., would prove more generally true; and it would be seen that kinds of disease hitherto unrecognised axe to be distinguished by their clinical history and features when anatomy fails to indicate their distinctness.

These remarks are suggested by the consideraticn of four cares of spinal disease at present under my care in Stephen ward, Guy's Hospital. These cases correspond more to the type of locomotor ataxia than to any other disease. But set three of them depart so much from the 